\title{
Assessment and Analysis of Use of Self-regulated Learning in Laboratory-based Extracurricular Undergraduate/First-year Graduate Research Projects
}

\section{Dr. Wookwon Lee P.E., Gannon University}

Wookwon Lee, P.E. received the B.S. degree in electronic engineering from Inha University, Korea, in 1985, and the M.S. and D.Sc. degrees in electrical engineering from the George Washington University, Washington, DC, in 1992 and 1995, respectively. He is currently a full professor in the Department of Electrical and Computer Engineering at Gannon University, Erie, PA. Prior to joining Gannon in 2007, he had been involved in various research and development projects in industry and academia for more than 15 years.

\section{Dr. Nicholas B. Conklin, Gannon University}

Nicholas B. Conklin received a B.S. in applied physics from Grove City College in 2001, and a Ph.D. in physics from Penn State University in 2009. He is currently an associate professor and chair of the Physics Department at Gannon University, Erie, PA. 


\title{
Assessment and Analysis of Use of Self-Regulated Learning in Laboratory-Based Extracurricular Undergraduate/First-year Graduate Research Projects
}

\begin{abstract}
This paper in the Research category examines student use of the self-regulated learning (SRL) skills as a case study. In the previous studies reported in the literature, students' SRL skills were often assessed by survey instruments that would primarily measure student's perception of metacognition. In this paper, we utilize two sets of survey questionnaires, focused on student perception and actual achievement, respectively, on use of SRL skills in order to determine if there are any discrepancies between student perception and actual uses of SRL skills. This work was motivated by observations from our previous pilot studies that, when a survey questionnaire primarily measuring student perception on metacognition was used for data collection, indicated that uses of SRL skills by two different groups of engineering students, such as those in senior year and freshman year, are at a comparable level, although they would have quite different levels of knowledge in engineering and relevant technical skills. Our survey results and analysis in this paper for a group of engineering students participating in extracurricular research projects show that there are indeed considerable discrepancies between student perception and actual achievement on use of SRL skills.
\end{abstract}

\section{Introduction}

\subsection{Prior Research on Use of SRL}

Self-regulated learning (SRL) is a term that describes the learning process that learners go through. Learners with SRL skills engage in cognitive and metacognitive functioning, and also regulate affective dimensions such as motivation, behavior, and emotion. SRL is also regarded as a complex repository of knowledge and skills for planning, implementing, monitoring, evaluating, and continually improving the learning process. Self-regulated learning has been studied over more than two decades in general classroom settings and various assessment methods exist in the literature. It is commonly agreed that self-regulation is a good predictor of student's academic success. For instance, relationships were examined in [1] among motivational orientation, selfregulated learning, and classroom academic performance, and their regression analyses revealed that self-regulation, self-efficacy, and test anxiety emerged as the best predictors of performance.

In recent years, studies on SRL have been extended to engineering education. For instance, in [2], various factors of SRL ability were investigated in terms of the relative importance and contributions to engineering college students' learning outcomes, using the ImportancePerformance Analysis (IPA) Matrix. In [3], SRL skills were applied to students in a specific engineering/computer-science course called, data structure, to assess their learning effectiveness in the course. Also, specifically for project-based courses integrating engineering design activities carried out in the curricular settings, SRL skills were applied for a pilot study in senior/capstone design courses (e.g., see [4], [5]) or introductory freshmen courses with small engineering projects as part of the coursework (e.g., see [7], [11]). These pilot studies reported that both seniors and freshmen in engineering used a reasonable level of SRL skills while carrying out their respective engineering projects. 


\subsection{Prior Survey Instrument to Assess Use of SRL}

Data collection for assessment of SRL skills is mostly carried out in a form of surveys but the actual questionnaires vary depending on the purposes and analytical models. For instance, a survey was used in [2] based on the Importance-Performance Analysis Matrix to identify priorities of SRL skills and in [6], surveys were used to assess the effectiveness of various software tools designed to support use of SRL skills. On the other hand, in [7], instead of utilizing a survey, SRL skills were qualitatively assessed from students' reflection papers on use of SRL skills through "Design Your Process For Becoming A World Class Engineering Student” project activities. In this paper, as our study is focused on SRL skills on engineering design activities in extracurricular research projects, we adopt a relatively simple survey instrument [8] that was developed and validated particularly for assessment of use of SRL skills in engineering design. Derived from a widely-used questionnaire for assessment of SRL in general classroom settings [9][10], it captures student's perception of metacognition along the cycle of engineering design which typically includes problem definition, conceptual design, preliminary design, detailed design, and design communication. This survey instrument was utilized in some prior pilot studies on use of SRL skills in engineering design in the classroom settings, including the study by the survey creator [4], as well as our prior studies in a senior design course [5] and a freshmen course [11]. In these pilot studies, five SRL features were used: 1) task interpretation, 2) planning strategies, 3) cognitive actions, 4) monitoring and fix-up strategies, and 5) criteria of success. Each SRL feature is further split into two subcategories of activities in design process and team management. The resulting ten categories of questionnaire items are a subset of the Engineering Design Metacognitive Questionnaire (EDMQ) [8] and are considered suitable for evaluating use of SRL on engineering project activities. For the completeness of the context in this paper, those ten categories of questionnaire items are provided in Appendix. Four possible responses to the questionnaire items are converted to numerical scores on a scale of 1 to 4 as follows: 1: Almost Never; 2: Sometimes; 3: Often; 4: Almost Always.

In the prior pilot studies in [5][11], our analysis and comparison of data led to a conclusion that the use of SRL skills by two student groups, i.e., seniors and freshmen, is at a comparable level although their knowledge in engineering and relevant technical skills would be hugely different. One question arises -- Is the use of SRL skills by those two student groups in senior year and freshman year truly at a comparable level or is it due to the limitations of the survey instrument that primarily measures student perception? To answer this question, in this paper, we consider extracurricular research projects and collect data from two sets of questionnaires, including the one used in our pilot studies. Further details are described in Section 4.

\section{Description of Extracurricular Research Projects}

\subsection{Two NASA Mission-Related Projects}

Students working in our research lab have been engaged in two separate but related research projects. Both projects are grounded in the previous experience in designing payloads for use in high-altitude balloons. The first is a balloon payload to live-stream video from the solar eclipse that will traverse the United States on April 8, 2024. A second payload is a prototype designed to transmit data, including a live video feed, from a permanently shaded region (PSR) on the moon. Both projects are described in more detail below.

In 2017, a solar eclipse traversed the continental United States. Around 50 schools from across the nation, coordinated by Montana State University, collaborated to build and deploy high-altitude 
balloon payloads to live-stream video of the solar eclipse across the entire eclipse path. Our team contributed a set of payloads that employed a custom multi-modal tracking system and featured live-streaming videos from four cameras simultaneously. Videos from four additional cameras were recorded to an SD card, providing simultaneous coverage of the eclipse from eight different angles.

The multi-modal tracking system we designed utilized a 900MHz RF radio and an amateur Automatic Packet Reporting System (APRS) radio with position information coming from a GPS receiver. It also included an inexpensive cell phone with GPS that was designed to turn on once the payload landed, as operating a cell phone from a high-altitude balloon violates FCC regulations. The video payload was composed of four Raspberry Pi model 2B single board computers, each with two cameras. The Raspberry Pis were connected to an Ethernet switch, which was in turn connected to a $5.8 \mathrm{GHz}$ Ubiquiti Rocket M5 modem. A second M5 on the ground station received videos from all four Raspberry Pis. The bandwidth of the M5 only allowed for videos from four cameras to be transmitted, which is why videos from the other four cameras were stored in an SD card. This payload operated well during the eclipse (see [12][13] for more information on payload design and performance).

We have worked to refine our video payload design since the successful eclipse flight, anticipating that the updated payload can be used during the April 2024 solar eclipse. In particular, we have modified the design to be more reliable and easily reproducible. Much of the point-topoint wiring has been replaced with custom designed printed circuit boards, while the simple Styrofoam support structure has been replaced with laser-cut acrylic plates. We are also working towards building two additional ground station antennas to increase the range of line-of-sight (LOS) communication.

Based on the success of the eclipse payload, we have proposed a prototype payload to explore the interior of a PSR near the southern lunar pole as part of NASA's BIG Idea Challenge. Most PSRs occur inside large craters on the lunar surface. This payload prototype would employ a fourcamera live-streaming design similar to the eclipse payload, as well as a radiation detector based on other payloads we have successfully developed and flown [16]. One challenge of exploring PSRs is the lack of line-of-sight communication between a lander on the rim of a crater and any payload or rover that descends into the crater. Our proposed payload cleverly solves this problem by using a low frequency carrier signal $(\sim 140 \mathrm{MHz})$, resulting in a larger Fresnel zone and thus better refraction around obstructions, coupled with a small secondary payload deployed near the rim of the crater. The bandwidth limitations of the lower-frequency carrier signal will be overcome using orthogonal frequency-division multiplexing (OFDM). OFDM will allow the payload data from the primary payload to be transmitted over multiple subcarrier channels and then recombined at the secondary payload. The secondary payload is anticipated to communicate with the lunar lander via Wi-Fi over LOS, which can then relay the payload data back to Earth.

\subsection{Administration of Laboratory-Based Activities}

We have traditionally focused on working only with undergraduate students in our lab. However, in Fall 2018, we invited four graduate students to work on the project alongside the undergraduates. The number of graduate and undergraduate students working in our lab has fluctuated somewhat, with students joining and leaving the project according to their academic and personal needs. However, three of the graduate students from Fall 2018 persisted with the projects for three semesters (through the end of Fall 2019) until their graduation. While we anticipated that 
the graduate students would be able to mentor the undergraduates, we found that some graduate students did not have the requisite knowledge to provide leadership roles. In reality, the students appeared to function more-or-less as equals, with research experience and skill typically being more important than academic progress.

The research activities in our lab are entirely extracurricular. Both graduate and undergraduate students who choose to participate are expected to contribute a minimum of 5 hours per week, typically split over two days. From our many years of experience, this amount of time allows students to make meaningful contributions to the project without compromising their academic performance in the classroom. Several paid positions, funded through work study and external grants, are available for students who are willing to contribute 10 hours per week. At the start of each semester, lab hours are established based on student and faculty advisor availability. In order to remain in good standing with the project, students are expected to regularly attend assigned lab hours. Both faculty advisors also regularly attend lab hours, working side by side with students to mentor them in the research process and ensure that work is being completed on schedule. This setting helps students understand the importance of delivering assigned tasks in a timely fashion. We have found the combination of structured lab hours and close faculty-student interaction to be extremely effective in educating students and completing interesting projects.

\section{Assessment on Use of SRL: Data and Analysis}

\subsection{Survey Instruments}

Our laboratory-based extracurricular projects are considered well suited for the purpose of assessing SRL as they have been carried out as undergraduate research or first-year graduate research and involve more open-ended problems to solve than other engineering projects carried out in the curricular settings. Adopting the same survey instrument used in our previous studies [5][11], we first assess student perception on the use of SRL skills at the time of answering the first questionnaire. For assessment of actual achievements in the same SRL categories as those in the first instrument, we compose another survey questionnaire derived from the first instrument with minor revision to the questions focusing on what and how they did by the time of answering the second questionnaire. To discourage "perception on achievement," for each question in Questionnaire 2, we added the following statement with proper space to answer: "If your answer to the above question is either "3-Often" or "4-Almost Always," please provide an example task with a short answer. If you cannot quickly think of an example, please consider revising your response." Those two questionnaires were distributed in a single package but the question numbers in the second questionnaire were pseudo-randomized. For the purposes of comparison and referencing in the sections below, the second questionnaire items are provided along with the first questionnaire items side by side in Appendix.

\subsection{Analysis of Data from Surveys}

The surveys were completed by all 8 students in the project team including 5 graduate students (year 1 or 2 in the Master's degree program) and 3 undergraduate engineering students. Among them, there were 3 female and 5 male students; 3 of them were domestic students and 5 of them were international students. For a total of 40 questions in 10 categories, average scores and standard deviations were calculated for individual questions and also for each category. The results are summarized in Table 1 where the survey categories are labeled by Roman numerals and individual questions are sequentially labeled with a prefix $Q$. The average and standard deviation for "Overall" are for the category. For a comparison between the results from the two 
questionnaires, the averages and standard deviations were presented in two sets of columns, denoted by "Perception" (questionnaire 1) and "Achievement" (questionnaire 2).

For intuitive understanding from these numerical results, we consider that, as in [5][11], the average scores greater than or equal to 3.0 and less than 3.5 (i.e., $3.0 \leq$ average score $\mathrm{x}<3.5$ ) represent a "reasonable level" in using SRL skills; average scores below 3.0 represent "room for improvement"; and average scores greater than or equal to 3.5 represent a "highly desirable" level. It should be noted, though, that the average score of 3.0 set as the threshold for intuitive rating is our own choice, without rigorous validation, based on the scores assigned to the four possible answers, i.e., 1: Almost Never; 2: Sometimes; 3: Often; 4: Almost Always. We assumed that

Table 1. Summary of Survey Results on "Student Perception" and "Actual Achievements" on Use of SRL Skills: Average and Standard Deviations

\begin{tabular}{|c|c|c|c|c|c|c|c|c|c|c|c|c|c|c|}
\hline \multirow[b]{2}{*}{ Q's } & \multicolumn{2}{|c|}{ Perception } & \multicolumn{2}{|c|}{ Achievement } & \multirow[b]{2}{*}{ Q's } & \multicolumn{2}{|c|}{ Perception } & \multicolumn{2}{|c|}{ Achievement } & \multirow[b]{2}{*}{ Q's } & \multicolumn{2}{|c|}{ Perception } & \multicolumn{2}{|c|}{ Achievement } \\
\hline & Av. & $\begin{array}{l}\text { Std. } \\
\text { Dev }\end{array}$ & Av. & $\begin{array}{l}\text { Std. } \\
\text { Dev }\end{array}$ & & Av. & \begin{tabular}{l|} 
Std. \\
Dev
\end{tabular} & Av. & $\begin{array}{l}\text { Std. } \\
\text { Dev }\end{array}$ & & Av. & \begin{tabular}{|c|} 
Std. \\
Dev
\end{tabular} & Av. & $\begin{array}{l}\text { Std. } \\
\text { Dev }\end{array}$ \\
\hline \multicolumn{5}{|c|}{$\begin{array}{c}\text { I. (TI) Task Interpretation: Across } \\
\text { Design Phases }\end{array}$} & Q14 & 3.88 & 0.33 & 3.13 & 0.93 & Q28 & 3.13 & 0.60 & 3.00 & 0.87 \\
\hline Q1 & 3.13 & 0.93 & 2.88 & 0.78 & $\overline{Q 15}$ & 3.50 & 0.50 & 2.75 & 0.97 & Q29 & 3.38 & 0.86 & 2.25 & 0.97 \\
\hline Q2 & 3.25 & 0.66 & 3.00 & 1.00 & Q16 & 3.63 & 0.48 & 3.13 & 0.78 & Overall & 3.25 & 0.77 & 2.70 & 1.05 \\
\hline Q3 & 3.50 & 0.71 & 2.38 & 0.86 & & 3.67 & 0.47 & 3.00 & 0.91 & \multicolumn{5}{|c|}{$\begin{array}{l}\text { VIII. (MF) Monitoring and Fix-Up } \\
\text { Strategies: Across Team } \\
\text { Management Components }\end{array}$} \\
\hline Q4 & 3.63 & 0.70 & 2.69 & 0.90 & \multicolumn{5}{|c|}{$\begin{array}{l}\text { V. (CA) Cognitive Actions: Across } \\
\text { Design Phases }\end{array}$} & Q30 & 3.50 & 0.71 & 3.25 & 0.97 \\
\hline Q5 & 3.25 & 0.66 & 3.00 & 1.00 & Q17 & 3.75 & 0.43 & 2.75 & 1.09 & Q31 & 3.50 & 1.00 & 2.88 & 0.93 \\
\hline Overall & 3.35 & 0.76 & 2.79 & 0.94 & Q18 & 3.50 & 0.71 & 3.13 & 0.93 & Q32 & 3.25 & 0.97 & 2.25 & 0.83 \\
\hline \multicolumn{5}{|c|}{$\begin{array}{l}\text { II. (TI) Task Interpretation: Across } \\
\text { Team Management Components }\end{array}$} & Q19 & 2.63 & 0.99 & 2.88 & 1.17 & Overall & 3.42 & 0.91 & 2.79 & 1.00 \\
\hline Q6 & 3.63 & 0.48 & 2.88 & 0.93 & Q20 & 3.13 & 0.60 & 3.00 & 0.87 & \multicolumn{5}{|c|}{$\begin{array}{c}\text { IX. (CS) Criteria of Success: Across } \\
\text { Design Phases }\end{array}$} \\
\hline Q7 & 4.00 & 0.00 & 3.38 & 0.70 & Q21 & 2.75 & 0.97 & 2.63 & 1.11 & Q33 & 3.38 & 0.73 & 2.75 & 0.90 \\
\hline Q8 & 3.75 & 0.43 & 3.38 & 0.70 & Dverall & 3.15 & 0.88 & 2.88 & 1.05 & Q34 & 2.88 & 0.70 & 2.88 & 0.88 \\
\hline Overall & 3.79 & 0.41 & 3.21 & 0.82 & \multicolumn{5}{|c|}{$\begin{array}{l}\text { VI. (CA) Cognitive Actions: Across } \\
\text { Team Management Components }\end{array}$} & Q35 & 3.63 & 0.49 & 2.75 & 0.73 \\
\hline \multicolumn{5}{|c|}{$\begin{array}{c}\text { III. (PS) Planning Strategies: Across } \\
\text { Design Phases }\end{array}$} & Q22 & 3.13 & 1.05 & 3.13 & 0.93 & Q36 & 3.63 & 0.49 & 3.00 & 0.93 \\
\hline Q9 & 3.38 & 0.70 & 3.38 & 0.70 & Q23 & 3.75 & 0.43 & 2.50 & 0.87 & Q37 & 3.25 & 0.83 & 2.75 & 1.05 \\
\hline Q10 & 3.43 & 0.90 & 3.00 & 0.87 & Q24 & 3.38 & 0.70 & 2.75 & 1.09 & Overall & 3.35 & 0.73 & 2.83 & 0.95 \\
\hline Q11 & 3.25 & 0.66 & 3.25 & 0.83 & Overall & 3.42 & 0.81 & 2.79 & 1.00 & \multicolumn{5}{|c|}{$\begin{array}{l}\text { X. (CS) Criteria of Success: Across } \\
\text { Team Management Components }\end{array}$} \\
\hline Q12 & 3.25 & 0.66 & 3.25 & 0.66 & \multicolumn{5}{|c|}{$\begin{array}{l}\text { VII. (MF) Monitoring and Fix-Up } \\
\text { Strategies: Across Design Phases }\end{array}$} & Q38 & 3.13 & 0.76 & 3.13 & 0.76 \\
\hline Q13 & 3.50 & 0.71 & 3.00 & 0.87 & Q25 & 3.38 & 0.86 & 2.75 & 1.09 & Q39 & 3.63 & 0.49 & 3.00 & 0.76 \\
\hline Overall & 3.36 & 0.73 & 3.18 & 0.80 & Q26 & 3.25 & 0.83 & 3.13 & 0.93 & Q40 & 3.88 & 0.35 & 3.25 & 0.83 \\
\hline $\begin{array}{r}\text { IV. }(\text { PS }) \\
\text { Team }\end{array}$ & an & 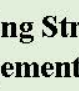 & $\begin{array}{l}\text { ggie } \\
\text { om! }\end{array}$ & $\begin{array}{l}\text { oss } \\
\text { ts }\end{array}$ & Q27 & 3.13 & 0.60 & 2.38 & 1.11 & Overall & 3.54 & 0.64 & 3.13 & 0.78 \\
\hline
\end{tabular}


participant responses with Often or Almost Always to a specific question indicate a good use of the SRL skills implied by the specific questionnaire item.

As shown in Table 1, in the category of Task Interpretation across Design Phases, students rated themselves with, on average, 3.13 3.63 for the questions Q1 Q5 in Questionnaire 1 (perception) but with $2.38 \sim 3.0$ for the questions Q1 Q5 in Questionnaire 2 (achievement). In particular, Q3 (3.50 v. 2.38) and Q4 (3.63 v. 2.69) show huge discrepancies between what students perceived in using the corresponding SRL skills and what actually they did. In other words, based on the average scores for Q3 as an example, one would believe that, when students work on a selected design, they would mostly build and analyze the chosen design model; but the reality is that may not be the case and they would only do it sometimes. Similarly, for Q4 as another example, one would believe that, when students finalize their design, they would mostly refine and optimize the investigated design; but the reality is that they would only do it sometimes. Also, the standard deviations for all items in this category are relatively high $(0.66 \sim 0.93$ for Perception v. .78 1.0 for Achievement) which indicate a mixed level of using SRL skills among the students in the category of task interpretation during design phases.

In the category of Task Interpretation across Team Management Components, the responses to Q7 and Q8 are comparable although student perceptions on use of the corresponding SRL skills (i.e., seek relevant resources; do a fair share) appear to be higher than what they actually did. However, once again, the responses to Q6 show a considerable discrepancy (3.63 v. 2.88). That is, students perceive that they would properly contribute to the completion of the assigned design tasks in a timely manner but the reality may be that they only do sometimes (if somewhat negatively interpreted, they occasionally fail to do so).

In a similar fashion, additional observations can be easily made on the numerical results in the other categories. We noticed several highlights. First, in addition to Q3, Q4, and Q6 mentioned above, considerable discrepancies occurred for Q15 (identify potential resources to complete the design project), Q17 (collect relevant measurements), Q23 (search for, select, and use working materials/tools, information, and funding sources needed), Q24 (negotiating the role), Q25 (clarify the design goals), Q27 (judge whether my design model reflects my final design), Q29 (think about how I could improve the design communication), Q31 (ask myself if I have found and selected appropriate resources), Q32 (ask whether the negotiation I made to determine my role is fair), Q33 (able to develop a list of final design goals), Q35 (able to develop a model that reflects the actual final design), and Q37 (able to produce a final written design report, etc.). Second, students rated themselves with low scores for both perception and achievement in Q19 (develop and use physical/mathematical models), Q21 (draft a final design report), and Q34 (able to consider all possible design solutions). Finally, no considerable discrepancy was observed in Q1 (3.13 v. 2.88; identify the design goals) but the response could be interpreted as "need improvement." Overall, these discrepancies or low scores in 19 out of 40 SRL skills surveyed in the questionnaire can be interpreted as either students need to further improve their skills or proper opportunities were not provided for students to apply their SRL skills.

On the other hand, students appeared to actually do reasonably well in other 21 out of 40 surveyed items, i.e., Q2 (look for possible design alternatives), Q5 (communicate the processes and outcomes), Q7 (seek relevant resources needed), Q8 (do my fair share), Q9 (read the design description), Q10 (identify my options), Q11 (collect the design requirements, assumptions, or specifications), Q12 (identify necessary adjustments needed), Q13 (identify, gather, and organize 


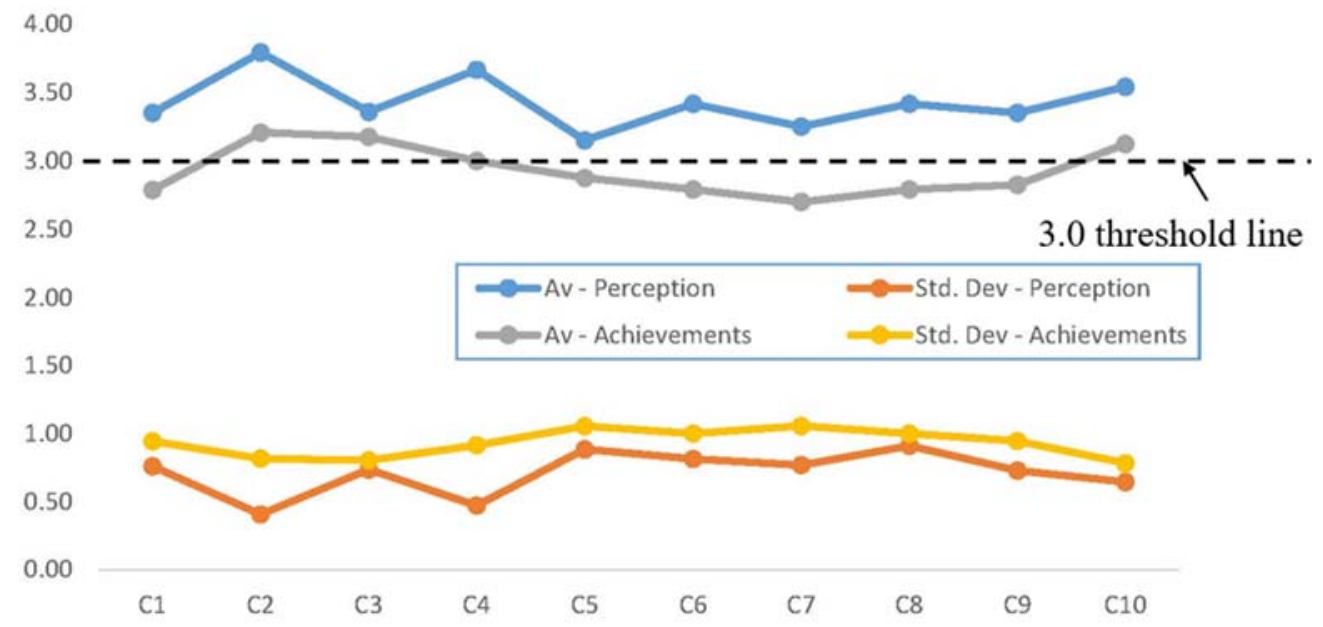

Figure 1. Comparison of student perception with actual achievement - categories on the horizontal axis are represented by prefix ' $\mathrm{C}$ '; the vertical axis represents average scores.

the information that needs to be communicated), Q14 (ensure to have a working schedule), Q16 (identify and clarify my part), Q18 (search for potential ways to better solve), Q20 (fine-tune the design), Q22 (estimate the time needed to accomplish), Q26 (determine whether to look for alternatives), Q28 (judge whether further adjustments are needed to improve), Q30 (think about how much time is left), Q36 (able to come up with a detailed and optimized design), Q38 (my contribution have helped), Q39 (find and use relevant resources), and Q40 (able to do my fair share). Also, one can note that some similar SRL skills, e.g., Q7 (seek relevant resources in the Task Interpretation category; 4.0 v. 3.38) and Q15 (identify potential resources in the Planning Strategies category; 3.5 v. 2.75), are not consistently applied during the engineering design cycle.

Having reviewed scores for individual questions so far, we will now review the category scores and compare them. Figure 1 shows all 10 categories for Perception and Achievement. From the two curves for averages, one can see that there are consistent discrepancies between Perception and Achievement. Also, 6 out of 10 categories scored on average below the 3.0 threshold, meaning that students would need further improvement in each of those categories. Only in C2, C3, and C10, students appeared to do reasonably well.

We also briefly compared the current results on student perception from extracurricular research with our previous results from senior capstone [5] and freshmen [11] courses. Shown in Figure 2, all average scores are above the 3.0 threshold line. As these curves are clustered closely above the 3.0 threshold, this would lead to a conclusion that all three groups of students are at a reasonable level in using SRL skills. But deducing from our observation above, there could be considerable discrepancies as well between perception and actual achievement in the student groups of seniors and freshmen - this conjecture is not substantiated yet due to no data available at the time of writing this paper and is subject to further research.

\subsection{Cohen's Kappa for Evaluation of Agreement between the Results}

Having observed consistent discrepancies between Perception and Achievement in the previous section, we further analytically evaluate agreement between them utilizing Cohen's kappa [14]. Cohen's kappa is an analytical technique used to quantify similarities and/or dissimilarities 


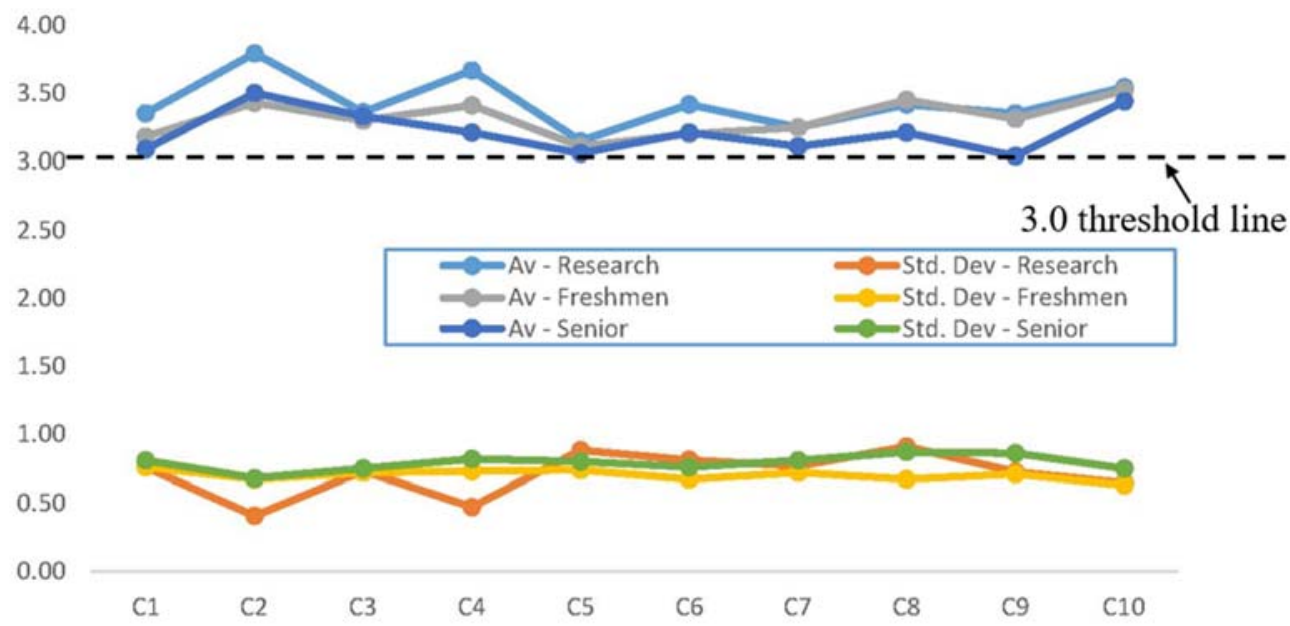

Figure 2. Comparison of student perceptions among three different groups - freshmen [11], senior [5], and extracurricular research; categories on the horizontal axis are represented by prefix ' $C$ '; the vertical axis represents average scores.

between two assessment results and has been previously applied to student learning from the activities performed by a common group of students [15][16]. The original Cohen's kappa coefficient is a statistic which measures inter-rater agreement for qualitative (categorical) items and is intended to measure the agreement between two raters who, respectively, classify $\mathrm{N}$ items into $\mathrm{C}$ mutually exclusive categories. In our application of Cohen's kappa, a rater (i.e., student) evaluates his/her uses of SRL skills in two related questionnaires of 40 qualitative statements to quantify the degree of the strength of agreement/disagreement on student's perception and achievement.

The value of Cohen's kappa is calculated by [14][15]

$$
\kappa=\frac{p_{o}-p_{e}}{1-p_{e}}
$$

where $p_{o}$ is the relative number of observations in agreement and $p_{e}$ is the probability of an agreement occurring by chance. For each question in the questionnaire, Cohen's kappa can be calculated as illustrated in [16]. In interpreting the value of Cohen's kappa, the most widely cited interpretation [17] is that the best possible strength of agreement between raters is when $\kappa=1.0$, values in the range of $0<\kappa<1.0$ represent varying levels of agreement from slight to substantial, and $\kappa<0$ indicates poor agreement [15].

Table 2 shows a summary of all kappa values for 40 questionnaire items in this study, presented in descending order and grouped for three ranges of kappa values with color codes, i.e., i) questions with $\kappa>0.40$ in yellow (for "reasonably good agreement"), ii) questions with $0.0<\kappa$ $\leq 0.40$ in white (for "slight agreement"), and iii) questions with $-1.0<\kappa \leq 0.00$ in blue (for "poor agreement"). First, we note that among 40 questions, only 9 questions (i.e., those coded with yellow) show a reasonably good agreement between Student Perception and Student Achievement, and 10 of 40 questions (i.e., those coded with blue) are indeed in poor agreement, and 21 of 40 are in between. Overall, this set of kappa values suggests that student perceptions and achievements do not agree well on use of SRL skills. 
To compare kappa values with the earlier assessments in subsection 3.2, we list them in 3 groups as follows. That is, group (a) is a set of questions showing good use of SRL skills as both averages for perception and achievement were above 3.0; group (b) is a set of questions showing need for improvement in use of SRL skills as achievement averages were below 3.0; and group (c) is a set of questions also needing improvement as both average scores were below 3.0. In addition, to overlap the results from kappa value-based classification of agreement in Table 2, we use superscripts for (i) and (iii), i.e., $\mathrm{Q}^{(\mathrm{i})}$ and $\mathrm{Q}^{(\mathrm{iii})}$ :
Table 2. Cohen's kappa values (calculated from the survey data from all participants)

\begin{tabular}{|l|l|l|l|l|l|l|l|}
\hline Q & kappa & Q & kappa & Q & kappa & Q & kappa \\
\hline Q26 & 0.800 & Q19 & 0.304 & Q5 & 0.167 & Q7 & 0.000 \\
\hline Q11 & 0.619 & Q8 & 0.294 & Q35 & 0.167 & Q16 & 0.000 \\
\hline Q22 & 0.600 & Q40 & 0.294 & Q32 & 0.143 & Q23 & 0.000 \\
\hline Q12 & 0.579 & Q20 & 0.289 & Q6 & 0.130 & Q25 & 0.000 \\
\hline Q30 & 0.579 & Q15 & 0.273 & Q31 & 0.111 & Q33 & -0.021 \\
\hline Q10 & 0.500 & Q17 & 0.273 & Q24 & 0.077 & Q21 & -0.034 \\
\hline Q28 & 0.467 & Q37 & 0.273 & Q27 & 0.077 & Q2 & -0.067 \\
\hline Q1 & 0.455 & Q34 & 0.256 & Q36 & 0.070 & Q29 & -0.098 \\
\hline Q13 & 0.429 & Q4 & 0.220 & Q3 & 0.059 & Q14 & -0.143 \\
\hline Q9 & 0.368 & Q18 & 0.179 & Q38 & 0.048 & Q39 & -0.333 \\
\hline
\end{tabular}

a) Good use of SRL skills (both averages above 3.0; regardless of discrepancy) - $\left\{\mathrm{Q}^{(\mathrm{iii})} 2, \mathrm{Q} 5, \mathrm{Q}^{(\mathrm{iii})} 7, \mathrm{Q} 8, \mathrm{Q} 9, \mathrm{Q}^{(\mathrm{i})} 10, \mathrm{Q}^{(\mathrm{i})} 11\right.$, $\left.\mathrm{Q}^{(\mathrm{i})} 12, \mathrm{Q}^{(\mathrm{i})} 13, \mathrm{Q}^{(\mathrm{iii})} 14, \mathrm{Q}^{(\mathrm{iii})} 16, \mathrm{Q} 18, \mathrm{Q}^{20}, \mathrm{Q}^{(\mathrm{i})} 22, \mathrm{Q}^{(\mathrm{i})} 26, \mathrm{Q}^{(\mathrm{i})} 28, \mathrm{Q}^{(\mathrm{i})} 30, \mathrm{Q} 36, \mathrm{Q} 38, \mathrm{Q}^{(\mathrm{iii})} 39, \mathrm{Q} 40\right\}$

b) Need improvement for SRL skills (perception average above 3.0 and achievement average below 3.0; large discrepancy) - $\left\{\mathrm{Q}^{(\mathrm{i})} 1, \mathrm{Q} 3, \mathrm{Q} 4, \mathrm{Q} 6, \mathrm{Q} 15, \mathrm{Q} 17, \mathrm{Q}^{\text {(iii) }} 23, \mathrm{Q} 24, \mathrm{Q}^{\text {(iii) }} 25, \mathrm{Q} 27\right.$,

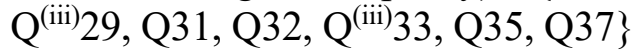

c) Need improvement for SRL skills (both averages below 3.0) - $\left\{\mathrm{Q} 19, \mathrm{Q}^{(\mathrm{iii})} 21, \mathrm{Q} 34\right\}$

From this, one can see that, as kappa values are intended to evaluate agreement, most questions with a relatively high value $\left(\kappa>0.40\right.$, indicated by $\mathrm{Q}^{(\mathrm{i})}$ ) appear in group (a)-good use of SRL skills; but also one can note that questions in poor agreement (indicated by $\mathrm{Q}^{(\mathrm{iii})}$ ) appear in all three groups (a), (b), and (c), meaning that, in group (a), some questions indicating good use of SRL skills still experience discrepancy while their average scores exceed the 3.0 threshold; in group (c), while Q21 has similar low average scores between perception and achievement (i.e., 2.75 v. 2.63), the actual agreement is also poor. It should be noted that both assessments, one based on average score compared against the 3.0 threshold and the other based on kappa values, are not meant to produce the same conclusion; rather, they are complementary in such a way that the former is primarily for the strength in student use of SRL skills and the latter is only for the degree of agreement between student perception and achievement.

\subsection{Brief Comments on Undergraduate and Graduate Students on Use of SRL}

With only 3 undergraduate students among the total 8 students who participated in the survey, the sample size for undergraduate students was too small for any statistical significance.

Nonetheless, Table 3 and Figure 3 show the category average scores and standard deviations from the same survey data presented in subsection 3.2 on student perception and achievement but separated for graduate (GR, dashed lines) and undergraduate (UG, solid lines) students. One interesting observation we note is that the discrepancies in averages between perception and achievement for undergraduate students are substantially narrower than those of graduate students in categories 5 10. More research would be required with sufficiently larger sample sizes of survey participants for statistical significance. 
Table 3. Summary of Survey Results on Graduate and Undergraduate "Student Perception" and "Actual Achievements" on Use of SRL Skills

\begin{tabular}{|c|cc|cc|cc|cc|}
\hline \multirow{3}{*}{ Category } & \multicolumn{4}{|c|}{ Perception } & \multicolumn{4}{c|}{ Achievement } \\
\cline { 2 - 9 } & $\begin{array}{c}\text { Average } \\
\text { GR }\end{array}$ & $\begin{array}{c}\text { Std. Dev } \\
\text { GR }\end{array}$ & $\begin{array}{c}\text { Average } \\
\text { UG }\end{array}$ & $\begin{array}{c}\text { Std. Dev } \\
\text { UG }\end{array}$ & $\begin{array}{c}\text { Average } \\
\text { GR }\end{array}$ & $\begin{array}{c}\text { Std. Dev } \\
\text { GR }\end{array}$ & $\begin{array}{c}\text { Average } \\
\text { UG }\end{array}$ & $\begin{array}{c}\text { Std. Dev } \\
\text { UG }\end{array}$ \\
\hline C1 & 3.24 & 0.86 & 3.53 & 0.50 & 2.82 & 0.90 & 2.73 & 1.00 \\
C2 & 3.80 & 0.40 & 3.78 & 0.42 & 3.27 & 0.77 & 3.11 & 0.87 \\
C3 & 3.28 & 0.72 & 3.50 & 0.73 & 3.16 & 0.83 & 3.20 & 0.75 \\
C4 & 3.73 & 0.44 & 3.56 & 0.50 & 3.13 & 0.96 & 2.78 & 0.79 \\
C5 & 3.08 & 0.93 & 3.27 & 0.77 & 2.60 & 1.06 & 3.33 & 0.87 \\
C6 & 3.67 & 0.60 & 3.00 & 0.94 & 2.87 & 1.09 & 2.67 & 0.82 \\
C7 & 3.20 & 0.80 & 3.33 & 0.70 & 2.52 & 1.06 & 3.00 & 0.97 \\
C8 & 3.60 & 0.88 & 3.11 & 0.87 & 2.80 & 0.98 & 2.78 & 1.03 \\
C9 & 3.52 & 0.64 & 3.07 & 0.77 & 2.72 & 0.96 & 3.00 & 0.89 \\
C10 & 3.67 & 0.60 & 3.33 & 0.67 & 2.93 & 0.77 & 3.44 & 0.68 \\
\hline
\end{tabular}

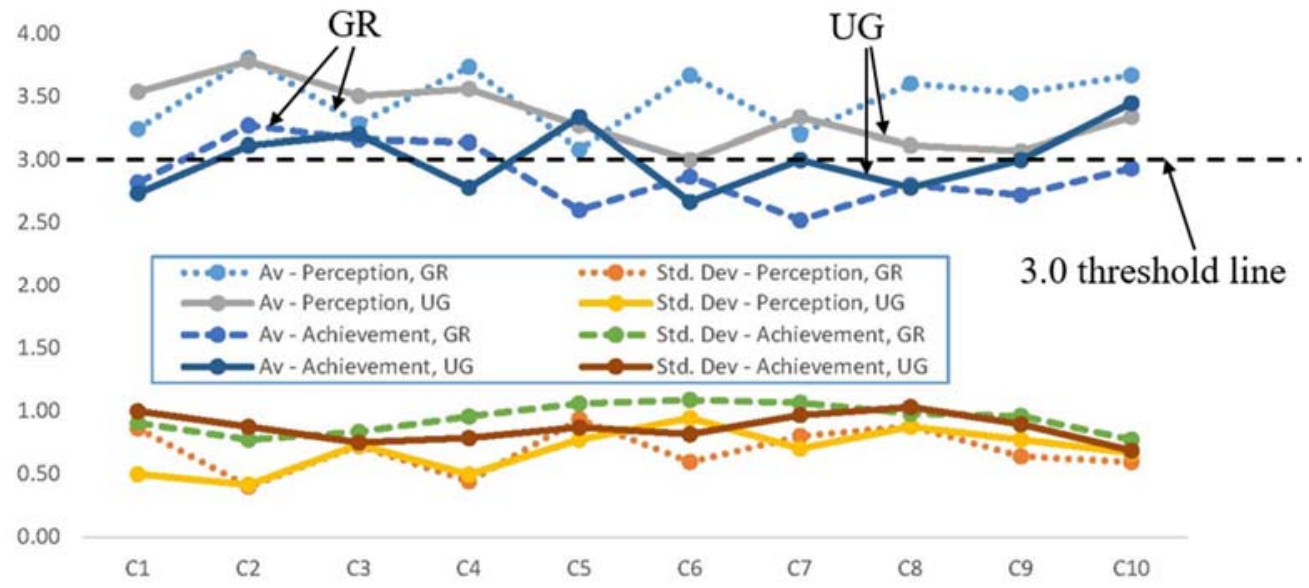

Figure 3. Comparison of perception with actual achievement between graduate and undergraduate students

\section{Concluding Remarks}

We have presented a case study of evaluating the self-regulated learning in extracurricular research projects utilizing two survey questionnaires. Our survey results showed that there are considerable discrepancies between student perception and actual achievements on use of SRL skills. Although these survey results and analysis in this paper may be a limited case study, we believe that a proper interpretation of the survey results could certainly help engineering educators develop teaching interventions that effectively promote student awareness and use of SRL. Further research may be needed to evaluate the actual achievements in other extracurricular and/or curricular settings such as formal classes of senior design and first-year freshmen engineering courses that integrate engineering projects. Also, we hope that our approach to survey design 
relating perception to action serves as a useful example for other engineering educators interested in using this survey in their context or designing a survey using a similar approach.

\section{Acknowledgement}

The extracurricular projects described in this study were supported in part by a Pennsylvania Space Grant Consortium subaward \#5373-GU-NASA-K06H and a faculty research grant from the University.

\section{References}

[1] P.R. Pintrich and E.V. DeGroot, "Motivational and self-regulated learning components of classroom academic performance," J. of Educational Psychology, vol. 82, no. 1, pp. 33-40, 1990.

[2] N.-Y. Kim and S.R. Lee, "Determining the priority of self-regulated learning ability development for engineering college students using IPA," in Proc. 2015 International Conference on Interactive Collaborative Learning (ICL), September 20-24, 2015, Florence, Italy, pp. 598-601.

[3] I-H. Li, G.-H. Hwang, Y.-X. Lin, "Data Mining on the Prior Knowledge and the Effectiveness of the SelfRegulated Learning," in Proc. 4th International Conference on Industrial Engineering and Applications (ICIEA), April 21-23, 2017, Nagoya, Japan, pp. 275-278.

[4] O. Lawanto and A. Febrian, "Student self-regulation in Capstone design courses: A case study of two project teams," in Proc. IEEE Frontiers in Education Conference, Oct 12-15, 2016, Erie, PA, pp. 1-5.

[5] W. Lee, "Assessment of self-regulated learning in senior capstone design," in Proc. 8th Annual Process Education Conf., June 14-17, 2018, Erie, PA, pp. 1-8.

[6] M.M. Vázquez, M.C. Rodríguez, and M.L. Nistal, "Analysis of Self-Regulated Learning Strategies Oriented to the Design of Software Support," in Proc. 2014 Frontiers in Education Conf. (FIE), Oct. 22-25, 2014, Madrid, Spain, pp. 1-9.

[7] K. Arnsdorff, A. Chen, R. McCord, and S. Peuker, "Work in progress - Student description of self-regulated learning: A qualitative investigation of students' reflection on their first semester in engineering" in Proc. First-Year Experience Conf., August 6-8, 2017, Daytona Beach, FL, pp. 1-5.

[8] O. Lawanto and H.B. Santoso, "Development and validation of the engineering design metacognitive questionnaire," in Proc. ASEE Annual Conference and Exposition, June 15-18, 2014, Indianapolis, IN, pp. 110.

[9] P.R. Pintrich, D. Smith, T. Garcia, and W. McKeachie, A Manual for the Use of the Motivated Strategies for Learning Questionnaire (MSLQ), The University of Michigan, Ann Arbor, MI, 1991.

[10] Paul R. Pintrich, A conceptual framework for assessing motivation and self-regulated learning in college students, Educational Psychology Review, Vol. 16, No. 4, pp. 385-406, December 2004.

[11] W. Lee, D. Gee, and S. Tiari, "Assessment of self-regulated learning in service-learning project in a first-year seminar in engineering course," in Proc. 2019 Frontiers in Education Conf. (FIE), Oct. 16-19, 2019, Cincinnati, OH, pp. 1-6.

[12] W. Lee, T. Batjargal, and N. Conklin, "Implementation of multimodal tracking capabilities for high-altitude ballooning," in Proc. Academic High-Altitude Conference, October 27-28, 2017, Minneapolis, MN, pp. 1-6.

[13] T. Batjargal, W. Lee, and N. Conklin, "Implementation of simultaneous multi-streaming of live solar eclipse video via 5.8 GHz AirMax," in Proc. Academic High-Altitude Conference, October 27-28, 2017, Minneapolis, $\mathrm{MN}$, pp. 1-8.

[14] J. Cohen, "A coefficient of agreement for nominal scales," Educational and Psychological Measurement, no. 20, pp. 37-46, 1960.

[15] S.J. Dickerson, S.P. Jacobs, A.M. Garcia and D.V.P. Sanchez, "Joint assessment and evaluation of senior design projects by faculty and industry," in Proc. 2016 Frontiers in Education Conf. (FIE), Erie, PA, pp. 1-7.

[16] W. Lee and N. Conklin, "Assessment of student learning experience in two exemplary engineering projects," in Proc. ASEE Annual Conference and Exposition, June 25 - 28, 2017, Columbus, OH, pp. 1-15.

[17] J.R. Landis and G.G. Koch, "The measurement of observer agreement for categorical data," Biometrics, no. 33, pp. 159-74, 1977. 


\section{Appendix}

\section{The two sets of survey questions used for the study in this paper are listed below for the referencing purposes.}

Table 4. Two sets of questionnaires used in this study

Survey on Student Perception
Q1: When I am defining my design problem, I need to identify
the design goals.
Q2: When I am generating solution ideas, I need to look for
possible design alternatives.
Q3: When I am working on my selected design, I need to build
and analyze the chosen design model.
Q4: When I am finalizing my design, I need to refine and
optimize the investigated design.
Q5: When I am communicating my design solution, I need to
communicate the processes and outcomes of my final design in detail.

Q6: When I am working with my team, I need to ensure that my contribution to the team will deliver the design tasks in a timely manner.

Q7: When I am working with my team, I need to seek relevant resources (e.g., materials/tools, information, skills, funding) needed.

Q8: When I am working with my team, I need to do my fair share in an overall team's effort to complete the project.

Q9: As I start defining my design problem, I read the design description (or brief) to identify design goals.

Q10: As I start generating solution ideas, I identify my options to come up with a better design solution.

Q11: As I start working on my selected design, I collect the design requirements, assumptions, or specifications for functions and the chosen design to develop a design model.

Q12: As I start finalizing my design, I identify necessary adjustments needed to optimize the chosen design.

Q13: As I start thinking about how to communicate my design solution, I identify, gather, and organize the information that needs to be communicated to various audiences such as my client, teacher, and friends.

Q14: As I start working with my team, I ensure that I have a working schedule to follow throughout the design process.

Q15: As I start working with my team, I identify potential resources (e.g., materials/tools, information, skills, funding) to complete the design project.

Q16: As I start working with my team, I identify and clarify my part in the team's effort to arrive at a solution.

Q17: When I am defining my design problem, I am collecting relevant measurements (or quantifications) of the design goals.

Q18: When I am generating solution ideas, I am searching for potential ways to better solve my design problems.

Q19: When I am working on my selected design, I am developing and using physical (or mathematical) models (representations) that represent the actual chosen design.

Q20: When I am finalizing my design, I am fine-tuning the design to produce better performance.

\section{Survey on Student's Achievement}

Q1: When I was defining my design problem, I did identify the design goals.

Q2: When I was generating solution ideas, I did look for possible design alternatives.

Q3: When I was working on my selected design, I did build and analyze the chosen design model.

Q4: When I was finalizing my design, I did refine and optimize the investigated design.

Q5: When I was communicating my design solution, I did communicate the processes and outcomes of my final design in detail.

Q6: When I was working with my team, I did ensure that my contribution to the team delivered the design tasks in a timely manner.

Q7: When I was working with my team, I did seek relevant resources (e.g., materials/tools, information, skills, funding) needed.

Q8: When I was working with my team, I did my fair share in an overall team's effort to complete the project.

Q9: As I started defining my design problem, I did read the design description (or brief) to identify design goals.

Q10: As I started generating solution ideas, I did identify my options to come up with a better design solution.

Q11: As I started working on my selected design, I did collect the design requirements, assumptions, or specifications for functions and the chosen design to develop a design model.

Q12: As I started finalizing my design, I did identify necessary adjustments needed to optimize the chosen design.

Q13: As I started thinking about how to communicate my design solution, I did identify, gather, and organize the information that needs to be communicated to various audiences such as my client, teacher, friends.

Q14: As I started working with my team, I did ensure that I have a working schedule to follow throughout the design process.

Q15: As I started working with my team, I did identify potential resources (e.g., materials/tools, information, skills, funding) to complete the design project.

Q16: As I started working with my team, I did identify and clarify my part in the team's effort to arrive at a solution.

Q17: When I was defining my design problem, I was collecting relevant measurements (or quantifications) of the design goals.

Q18: When I was generating solution ideas, I was searching for potential ways to better solve my design problems.

Q19: When I was working on my selected design, I was developing and using physical (or mathematical) models (representations) that represented the actual chosen design.

Q20: When I was finalizing my design, I was fine-tuning the design to produce better performance. 
Q21: When I am communicating my design solution, I am drafting a final design report, creating drawings, or developing an oral presentation.

Q22: When I am working with my team, I am estimating the time needed to accomplish each part of the design tasks.

Q23: When I am working with my team, I am searching for, selecting, and using working materials/tools, information, and funding sources we need.

Q24: When I am working with my team, I am negotiating the role that I have to play and tasks that I have to do with my teammates.

Q25: While I define my design problem, I am clarifying the design goals with design team/client.

Q26: While I generate solution ideas, I am determining whether I need to look for alternative design solutions.

Q27: While I work on my selected design, I am judging whether my design model reflects my final design.

Q28: While I finalize my design, I am judging whether further adjustments are needed to improve the design performance.

Q29: While I communicate my design solution, I am thinking about how I could improve the design communication and finalize the delivery of those communications.

Q30: While I work with my team, I am thinking about how much time is left, what I still have to do.

Q31: While I work with my team, I am asking myself if I have found and selected appropriate resources.

Q32: While I work with my team, I am asking myself whether the negotiation I made to determine my role in my team is fair and making necessary adjustment if needed.

Q33: After defining my design problem, I know that I have done a good job when I am able to develop a list of final design goals.

Q34: After generating solution ideas, I know that I have done a good job when I am able to consider all possible design solutions.

Q35: After working on my selected design, I know that I have done a good job when I am able to develop a model that reflects the actual final design.

Q36: After finalizing my design, I know that I have done a good job when I am able to come up with a detailed and optimized design.

Q37: After communicating my design solution, I know that I have done a good job when I am able to produce a final written design report, final drawings, or oral presentation to the client containing design information.

Q38: After working with my team, I know that I have done a good job when I ensure that my contribution have helped my team finish our design tasks on time.

Q39: After working with my team, I know that I have done a good job when I find and use relevant resources (e.g., materials/tools, information, skills, funding).

Q40: After working with my team, I know that I have done a good job when I am able to do my fair share in my team's accomplishments.
Q21: When I was communicating my design solution, I was drafting a final design report, creating drawings, or developing an oral presentation.

Q22: When I was working with my team, I was estimating the time needed to accomplish each part of the design tasks.

Q23: When I was working with my team, I was searching for, selecting, and using working materials/tools, information, and funding sources we needed.

Q24: When I was working with my team, I was negotiating the role that I had to play and tasks that I had to do with my teammates.

Q25: While I defined my design problem, I was clarifying the design goals with design team/client.

Q26: While I generated solution ideas, I was determining whether I needed to look for alternative design solutions.

Q27: While I work on my selected design, I was judging whether my design model reflected my final design.

Q28: While I finalized my design, I was judging whether further adjustments were needed to improve the design performance.

Q29: While I communicated my design solution, I was thinking about how I could improve the design communication and finalized the delivery of those communications.

Q30: While I worked with my team, I was thinking about how much time was left, what I still had to do.

Q31: While I worked with my team, I was asking myself if I had found and selected appropriate resources.

Q32: While I worked with my team, I was asking myself whether the negotiation I made to determine my role in my team was fair and making necessary adjustment if needed.

Q33: After defining my design problem, I knew that I had done a good job when I was able to develop a list of final design goals.

Q34: After generating solution ideas, I knew that I had done a good job when I was able to consider all possible design solutions.

Q35: After working on my selected design, I knew that I had done a good job when I was able to develop a model that reflected the actual final design.

Q36: After finalizing my design, I knew that I had done a good job when I was able to come up with a detailed and optimized design.

Q37: After communicating my design solution, I knew that I had done a good job when I was able to produce a final written design report, final drawings, or oral presentation to the client containing design information.

Q38: After working with my team, I knew that I had done a good job when I did ensure that my contribution had helped my team finish our design tasks on time.

Q39: After working with my team, I knew that I had done a good job when I did find and use relevant resources (e.g., materials/tools, information, skills, funding).

Q40: After working with my team, I knew that I had done a good job when I was able to do my fair share in my team's accomplishments. 